(RR:1.82, 95\% Cl:1.08-2.98), diseases of the musculoskeletal system and connective tissue (RR:1.49, 95\% Cl:1.05-2.05), and for injuries and poisoning (RR:1.46, 95\% Cl:1.01-2.06). While not significantly increased overall, hospitalizations for diseases of the circulatory system were significantly increased in patients with $\mathrm{pSS}$ aged $\geq 75$ years (RR:1.54, 95\% Cl: $1.11-2.11$ ).

Conclusions: Patients with pSS experienced higher rates of hospitalisation than the general population. Hospitalizations for endocrine/metabolic disorders, diseases of the circulatory system, diseases of the musculoskeletal system and connective tissue disorders, and injuries were more common among patients with pSS than comparators.

Disclosure of Interest: None declared

DOI: 10.1136/annrheumdis-2018-eular.2455

\section{SAT0696 ASSOCIATIONS BETWEEN ANTIBIOTICS FOR NON- TUBERCULOUS MYCOBACTERIAL INFECTION AND INCIDENT SJÖGREN'S SYNDROME: A NATIONWIDE, POPULATION-BASED CASE-CONTROL STUDY}

H.-H. Chen, W.-C. Chao. Department of Medical Research, Taichung Veterans General Hospital, Taichung, Taiwan, Province of China

Background: We recently reported an association between Sjögren's syndrome (SS) and prior nontuberculous mycobacterial (NTM) infection which was defined as having a diagnosis of NTM with concurrent combinational antibiotics therapy for NTM infection. However, whether the increased risk of SS was attributed to NTM infection or antibiotics used to treatment NTM infection was unknown.

Objectives: To address the association between use of antibiotics which can be used to treat NTM infection and the risk of newly diagnosed SS.

Methods: Using a nationwide, population-based, claims dataset, 5751 newly diagnosed SS were identified, and we further excluded those $(n=198)$ having a history of confirmed or suspected mycobacterial infection to avoid the confounding effect of NTM infection-associated incident SS as we previously identified. A total of 5,553 SS cases were enrolled and compared them with 83295 non-SS controls matched (1:15) for age, sex, and their year of first SS diagnosis date. The association between the risk of incident SS and antibiotics was determined by calculating odds ratios (ORs) with $95 \%$ confidence intervals (Cls) using conditional logistic regression analysis.

Results: After adjusting for potential confounders, the risk of SS was increased in patients treated with new macrolides (aOR 1.95, 95\% Cl 1.80-2.11), fluoroquinolones (aOR 1.52, 95\% Cl 1.41-1.64), and tetracyclines (aOR 1.69, 95\% Cl 1.591.79) compared with those in non-SS controls after adjusting for $\mathrm{CCl}$, bronchiectasis and Helicobacter pylori infection. Notably, we found that the association was consistent among each antibiotic in these three groups of antibiotics. In contrast to these three groups of antibiotics, usage of amikacin was found to have a negative association with incident SS (aOR 0.68, 95\% CI 0.53-0.87).

\begin{tabular}{|c|c|c|}
\hline & Model A & Model B \\
\hline & aOR $(95 \% \mathrm{Cl})$ & aOR $(95 \% \mathrm{Cl})$ \\
\hline New macrolide & & $\begin{array}{c}1.95(1.80- \\
2.11)\end{array}$ \\
\hline Clarithromycin & $\begin{array}{c}1.84(1.69- \\
2.01)\end{array}$ & \\
\hline Azithromycin & $\begin{array}{c}2.07(1.71- \\
2.51)\end{array}$ & \\
\hline Aminoglycoside & & $\begin{array}{c}0.68(0.53- \\
0.87)\end{array}$ \\
\hline Amikacin & $\begin{array}{c}0.58(0.41- \\
0.81)\end{array}$ & \\
\hline \multicolumn{3}{|l|}{ Streptomycin } \\
\hline Kanamycin & $\begin{array}{c}0.83(0.58- \\
1.19)\end{array}$ & \\
\hline Fluoroquinolone & & $\begin{array}{c}1.52(1.41- \\
1.64)\end{array}$ \\
\hline Ofloxacin & $\begin{array}{c}1.15(1.01- \\
1.32)\end{array}$ & \\
\hline Ciprofloxacin & $\begin{array}{c}1.34(1.17- \\
1.54)\end{array}$ & \\
\hline Levofloxacin & $\begin{array}{c}1.50(1.22- \\
1.85)\end{array}$ & \\
\hline Moxifloxacin & $\begin{array}{c}1.43(1.30- \\
1.56)\end{array}$ & \\
\hline Tetracycline & & $\begin{array}{c}1.69(1.59- \\
1.79)\end{array}$ \\
\hline Doxycycline & $\begin{array}{c}1.59(1.49- \\
1.70)\end{array}$ & \\
\hline Minocycline & $\begin{array}{c}1.48(1.35- \\
1.62)\end{array}$ & \\
\hline
\end{tabular}

Conclusions: New macrolides, fluoroquinolones and tetracyclines were associated with a higher incidence of SS, whereas usage of amikacin had a negative correlation. These findings indicated the need for vigilance of SS in prescribing these antibiotics to treat NTM and other infectious diseases and warrant further mechanistic studies.

\section{REFERENCES:}

[1] Mor A, Pillinger MH, Wortmann RL, Mitnick HJ. Drug-induced arthritic and connective tissue disorders. Semin Arthritis Rheum 2008;38(3):249-64.

[2] Chao WC, Lin CH, Lia TL, Chen YM, Chen DY, Chen HH. Association between a history of mycobacterial infection and the risk of newly diag nosed Sjogren's syndrome: a nationwide, population-based case-control study. PLoS ONE 2017;12(5):e0176549.

Acknowledgements: We thank for the statistical work by Biostatistics Task Force of Taichung Veterans

General Hospital, Taichung, Taiwan, ROC

Disclosure of Interest: None declared

DOI: 10.1136/annrheumdis-2018-eular.1105

\section{SAT0697 ASSOCIATION BETWEEN TONSILLITIS AND NEWLY DIAGNOSED ANKYLOSING SPONDYLITIS: A NATIONWIDE, POPULATION-BASED, CASE-CONTROL STUDY}

H.-H. Chen ${ }^{1,1,1}$, W.-C. Chao ${ }^{1}$, D.-Y. Chen ${ }^{2} .{ }^{1}$ Department of Medical Research;

${ }^{2}$ Department of Internal Medicine, Taichung Veterans General Hospital, Taichung, Taiwan, Province of China

Background: To date, two most commonly proposed environmental risk factors for ankylosing spondylitis (AS) include mechanical stress at the enthesis and infections. A recent Swedish study showed that childhood tonsillitis was associated with future development of AS. However, no Ascian study has reported this association.

Objectives: To investigate the association between tonsillitis and the risk of newly diagnosed AS.

Methods: We used 2003-2012 data from the Taiwanese National Health Insurance Database to perform a nationwide, population-based, case-control study. We identified AS patients newly diagnosed from 2005 to 2012 as the study group and selected sex, age and the year of index date matched $(1: 6)$ non-AS individuals as controls. Using conditional logistic regression analysis after adjustment for potential confounders, including a history of periodontitis, appendicitis, and Charlson comorbidity index $(\mathrm{CCl})$, we measured the association of AS risk with prior tonsillitis by calculating odds ratios (ORs) with $95 \%$ confidence intervals (Cls) Sensitivity analyses for the association between AS risk and tonsillitis were conducted by varying the definition of tonsillitis.

Results: We identified 37002 incident AS cases and 222012 matched non-AS controls. The risk of AS was associated with tonsillitis (OR, 1.80; 95\% Cl, 1.552.10) after adjustment for potential confounders. The association between AS risk and a history of tonsillitis remained significant by using various definitions of tonsillitis based on ICD9-CM Codes. Such associations were consistent across various subgroups stratified by age, sex, and a history of periodontitis or appendicitis.

Conclusions: The present study reveals an association between AS risk and prior tonsillitis.

\section{REFERENCE:}

[1] Lindstrom U, Exarchou S, Lie E, Dehlin M, Forsblad-d'Elia H, Askling J Jacobsson L. Childhood hospitalisation with infections and later develop ment of ankylosing spondylitis: a national case-control study. Arthritis research \& therapy $2016 ; 18: 240$

Acknowledgements: We would like to thank the Biostatistics Task Force of Taichung Veterans General Hospital, Taichung, Taiwan, ROC, for assistance with statistical analysis.

Disclosure of Interest: None declared

DOI: 10.1136/annrheumdis-2018-eular.1750

\section{SAT0698 MORTALITY OF PATIENTS WITH DIAGNOSED RHEUMATOID ARTHRITIS (RA) IN GERMANY 2012 ANALYSIS OF CLAIMS DATA FROM 60 MILLION PEOPLE}

I. Haase, G. Pongratz, O. Sander, M. Schneider, R. Brinks. Department of Rheumatology and Hiller Research Centre, University Hospital, Duesseldorf, Germany

Background: Mortality data of RA patients in Germany are sparse. Recently, data on the prevalence and incidence of RA comprising about $75 \%$ of the German population became available. ${ }^{1}$ In case of chronic diseases, it is possible to 